\title{
Osteonecrosis de la mandíbula asociada al tratamiento oral con ibandronato
}

\section{Osteonecrosis of the jaw associated with oral treatment with ibandronate}

\author{
O. Ribas-Deix ${ }^{1}$, P. Sanz-Gallén ${ }^{2}$, S. Noguée ${ }^{2}$
}

\section{Sr. Director:}

Los bifosfonatos constituyen un grupo de fármacos que inhiben la resorción ósea, a través de la supresión de la actividad de los osteoclastos. Se emplean para la reducción del dolor óseo, complicaciones esqueléticas en pacientes con mieloma múltiple, enfermedad de Paget, metástasis del cáncer de mama y de próstata, hipercalcemia y en el tratamiento de la osteoporosis postmenopáusica o secundaria al tratamiento crónico con corticoides ${ }^{1}$.

Entre los efectos adversos derivados del empleo de los bifosfonatos se encuentra la osteonecrosis maxilar. Dentro de este grupo de fármacos, los que se les relacionan con este efecto adverso son los que contienen en su molécula nitrógeno, siendo zoledronate, pamidronate, alendronate, risendronate e Ibandronate los implicados de mayor a menor frecuencia en la osteonecrosis de los maxilares ${ }^{24}$.

Se aporta el caso de una paciente con osteonecrosis de la mandíbula asociada a un tratamiento con ibandronato por vía oral.

Mujer de 82 años de edad, con antecedentes de artritis reumatoidea desde hacía
10 años y tratada con corticoterapia (deflazacort $6 \mathrm{mg} /$ día). Debido a una osteoporosis, desde hacía unos tres años se le administraba ibandronato por vía oral (150 $\mathrm{mg} / \mathrm{mes}$ ). Desde hacía 20 años, es controlada 2-3 veces/año por su médico estomatólogo para el tratamiento y seguimiento de enfermedades dentales y peridontales, practicándole exodoncias, obturaciones y tratamiento periodontal. Un mes después de instaurarle una prótesis total movible en el maxilar inferior, la paciente presentó una herida abierta en el lateral del lado izquierdo de la mandíbula. Se retira la prótesis esperando el cierre de la herida. A los 3 meses la paciente presenta dolor en la misma zona, se observa un aumento del tamaño de la herida. Se realizó un estudio radiológico mediante ortopantografía (Fig. 1) detectándose alteraciones compatibles con osteonecrosis de la mandíbula. Se realizó una biopsia de la zona observando, en la microscopia óptica, trabéculas óseas de diámetro variable, careciendo las lagunas de osteocitos y de osteoclastos. Estas trabéculas tenían la superficie erosionada y estaban en continuidad con material necrótico.

An. Sist. Sanit. Navar. 2011; 34 (3): 489-491

1. Médico Especialista en Estomatología. Barcelona.

2. Unidad de Toxicología. Hospital Clínico. Barcelona.

Recepción: 8 de julio de 2011

Aceptación provisional: 1 de agosto de 2011

Aceptación definitiva: 23 de agosto de 2011

\section{Correspondencia:}

Pere Sanz Gallen

Ronda General Mitre, 39

08017 Barcelona

E-mail. 17039psg@comb.es 
Se realizó un tratamiento conservador y tópico a base de clorhexidina al $0,12 \%$ (cada 12 horas) y antibioterapia (amoxicilina+clavulánico) durante dos semanas. La paciente presentó mejoría clínica con desaparición del dolor.

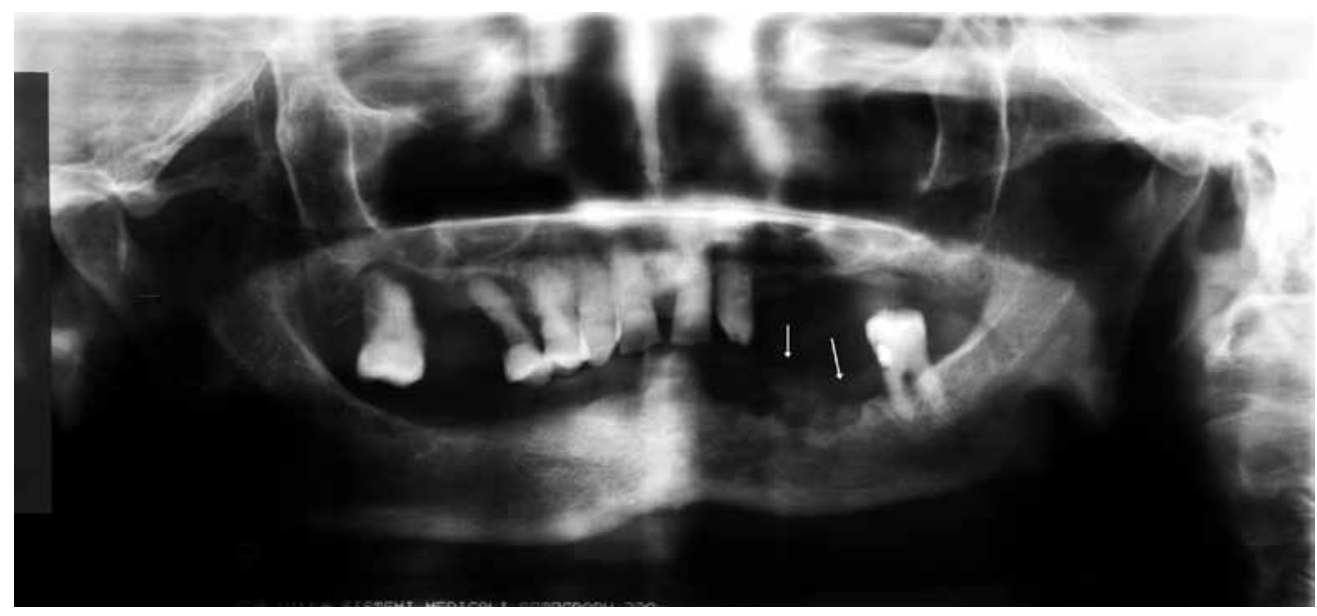

Figura 1. Ortopantografía que muestra un patrón moteado en el lado izquierdo de la mandíbula (flechas) compatible con osteonecrosis.

La aparición de una osteonecrosis de los maxilares en pacientes en tratamiento con bifosfonatos está condicionada por una serie de factores de riesgo que incrementan la probabilidad de padecer esta asociación, entre los que se encuentran el ser portador de un mieloma múltiple o un cáncer de mama, el tratamiento concomitante con corticoides, la administración por vía endovenosa y durante más de un año de bifosfonatos, el tratamiento con bifosfonatos por vía oral durante más de tres años y los antecedentes de cirugía dentoalveolar o patología inflamatoria (dental o peridontal $)^{5}$.

El diagnóstico de la osteonecrosis de los maxilares se realiza por las manifestaciones clínicas (en pacientes que no han sido tratados previamente con radioterapia en los maxilares $)^{6}$, pruebas complementarias como la realización de una ortopantografía o un $\mathrm{TAC}^{7}$. El diagnóstico se puede confirmar mediante el estudio histopatológico ${ }^{5}$. Pueden hacerse cultivos microbiológicos para descartar la sobreinfección bacteria- na o fúngica $\mathrm{y}$, en caso positivo, realizar un antibiograma y establecer la terapia adecuada $^{7}$. El diagnóstico diferencial debe establecerse con las osteonecrosis maxilares de origen tóxico-laboral, siendo las más características las de los trabajadores expuestos al fósforo inorgánico o al radio ${ }^{8,9}$.

Los pacientes a los que se les administre bifosfonatos, deben de practicar una buena higiene bucal y tratarse las afectaciones dentales y peridontales, con la finalidad de evitar este tipo de complicaciones ${ }^{3,5}$. El tratamiento de la osteonecrosis de los maxilares oscila desde un tratamiento conservador con antisépticos bucales, antibioterapia y analgésicos no esteroideos, hasta un tratamiento quirúrgico tras el cese en la administración de los bifosfonatos.

La AAOS (American Association of Oral and Maxillofacial Surgeons $)^{10}$ ha publicado un protocolo de actuación donde se describen las principales medidas preventivas y terapeúticas, en los pacientes con osteonecrosis maxilar asociada al tratamientos con bifosfonatos. 
Para evitar o minimizar al máximo la osteonecrosis maxilar por bifosfonatos, es fundamental que haya una estrecha colaboración entre los especialistas que prescriben dicho tratamiento, con el dentista, cirujano maxilofacial $u$ otros especialistas que tratan enfermedades dentales y/o peridontales.

\section{BIBLIOGRAFÍA}

1. Cardona F, Bagán JV, Sáinz E, Figuerido J, Giner F, VIDAN FJ. Osteonecrosis de los maxilares por bifosfonatos. Actualización y puesta al día. An Sist Sanit Navar 2009; 32: 423-437.

2. MarX RE. Pamidronate (Aredia) and zoledronate (Zometa) induced avascular necrosis of the jaws: a growing epidemic. J Oral Maxillofac Surg 2003; 61: 1115-1117.

3. NASE JB, SuzUKI JB. Osteonecrosis of the jaw and oral bisphosphonate treatment. J Am Dent Assoc 2006; 137: 1115-1119.

4. Malden NJ, PAI AY. Oral bisphosphonate associated osteonecrosis of the jaws: three case reports. Br Dent J 2007; 203: 93-97.
5. Junquera LM, Martín-Granizo R. Diagnosis, prevention, and treatment of bisphosphonateassociated osteonecrosis of the jaw. Recommendations of the Spanish Society of Oral and Maxillofacial Surgery (SECOM). Rev Esp Cir Oral Maxilofac 2008; 30: 145-156.

6. Brigoli A, Viviani C, Duvina M, Brancato L, SpineLLI G, BRANDi ML et al. Biphosphonates-related osteonecrosis of the jaw: clinical and physiopathological considetations. Ther Clin Risk Manag 2009; 5: 217-227.

7. SURLAN PoPOVICK, K. M. Imaging findings in bisphosphonate-induced osteonecrosis of the jaws. Radiol Oncol 2010; 44: 215-219.

8. Donoghue AM. Bisphosphonates and osteonecrosis: analogy to phossy jaw. Med J Aust 2005; 183: 163-164.

9. VANCE MA. Osteonecrosis of the jaw and bisphosphonates: A comparison with white phosphorus, radium, and osteopetrosis. Clin Toxicol 2007; 45: 753-762.

10. Ruggiero SL, Dobson TB, Assael LA, Landesberg R, Marx RE, Mebrotra B. American Association of Oral and Maxillofacial Surgeons Position Paper on Bisphosphanate-Related Osteonecrosis of the Jaws-2009 Update. J Oral Maxillofac Surg 2009; 67 (Suppl 1): 2-12. 